This item was submitted to Loughborough's Research Repository by the author.

Items in Figshare are protected by copyright, with all rights reserved, unless otherwise indicated.

\title{
Processing and characterization of nanostructured Grade 2 Ti processed by combination of warm isothermal ECAP and extrusion
}

PLEASE CITE THE PUBLISHED VERSION

https://doi.org/10.1016/j.msea.2017.07.088

\section{PUBLISHER}

(C) Elsevier

\section{VERSION}

AM (Accepted Manuscript)

\section{PUBLISHER STATEMENT}

This paper was accepted for publication in the journal Materials Science and Engineering: $A$ and the definitive published version is available at https://doi.org/10.1016/j.msea.2017.07.088

\section{LICENCE}

CC BY-NC-ND 4.0

\section{REPOSITORY RECORD}

Eftekhari, Mahroo, Ghader Faraji, S. Nikbakht, R. Rashed, R. Sharifzadeh, R. Hildyard, and Mahdi Mohammadpour. 2019. "Processing and Characterization of Nanostructured Grade 2 Ti Processed by Combination of Warm Isothermal ECAP and Extrusion". figshare. https://hdl.handle.net/2134/26011. 


\title{
Processing and characterization of nanostructured Grade 2 Ti processed
}

\section{by combination of warm isothermal ECAP and extrusion}

\author{
M. Eftekhari ${ }^{1}$, G. Faraji ${ }^{*}$, S. Nikbakht ${ }^{1}$, R. Amin ${ }^{1}$, R. Sharifzadeh ${ }^{1}$, M.
}

Mohammadpour $^{2}$, R. Hildyard ${ }^{2}$

${ }^{1}$ School of Mechanical Engineering, College of Engineering, University of Tehran, Tehran, 11155-4563, Iran.

${ }^{2}$ Wolfson School of Mechanical, Electrical \& Manufacturing Engineering, Loughborough University,

Loughborough, UK

*Corresponding author, email: ghfaraji@ut.ac.ir, Tel/Fax: +982161119966.

\begin{abstract}
In this study, combined multi pass equal channel angular pressing (ECAP), and subsequent warm extrusion at different temperatures are performed on commercial purity titanium. Mechanical and microstructural evolutions are then investigated. Since it was observed that the four passes ECAP processed sample showed the best strength and reasonable elongation, this sample was selected for studying the extrusion temperature effects on the structure and mechanical properties of Grade 2 titanium. Therefore, the 4th passes ECAP processed sample was extruded at different temperatures of $300{ }^{\circ} \mathrm{C}, 350{ }^{\circ} \mathrm{C}, 400{ }^{\circ} \mathrm{C}, 450{ }^{\circ} \mathrm{C}$ and $500{ }^{\circ} \mathrm{C}$. The result revealed that the best mechanical properties were achieved from the specimen processed by four passes ECAP followed by warm extrusion at $300^{\circ} \mathrm{C}$. The strength, and hardness of this sample were considerably improved in comparison with that of the unprocessed sample. Also, its ultra-fine grained and nanograined microstructure were homogeneous, with a grain size ranged from 40-200 nm with an average grain size of about $123 \mathrm{~nm}$. It was seen that the mechanical properties of some samples after applying this combined process (ECAP + warm extrusion) are
\end{abstract}


comparable with those of Grade 5 titanium which is commonly used in medical applications but contains alloying elements that are toxic to human health.

Keywords: Warm ECAP; Warm extrusion; Pure Ti; Mechanical properties; SEM; TEM.

\section{Introduction}

Titanium alloys are one of the most widely used alloys in aviation and biomedical applications. However, since most of the common alloying elements used in these alloys, such as $\mathrm{Al}$ and $\mathrm{V}$, are toxic to human health, many attempts have been made to find a substitute for the Ti-6Al-4V alloy. In recent years, there is a high tendency to use commercially pure titanium (CP-Ti) which has a lower cost and a better-expected corrosion resistance than Ti-6Al-4V, but its yield strength and ultimate tensile strength are much lower [1,2]. At present, the mechanical properties of CP-Ti grades can be improved to the same or sometimes better than Ti-6Al-4V by grain refinement, commonly achieved via severe plastic deformation (SPD) methods [3-5]. Among all of the SPD techniques, equal channel angular pressing (ECAP) is well suited in terms of grain refinement and subsequent improvement of the mechanical properties of CP-Ti [6]. The ECAP method came into operation during the 1970s, headed by Segal et al. [7, 8]. In subsequent studies, Semiatin et al. [9] reported that Grade 2 Ti underwent segmented failure when processed by ECAP in a die with channel angle of $90^{\circ}$ at all strain rates at room temperature. Raab et al. [7] observed that decreasing the temperature of ECAP process results in an increase of the hydrostatic pressure magnitude and a reduction of the average grain size. It was also shown that by applying ECAP process with a $90^{\circ}$ die channel angle on $\mathrm{CP}-\mathrm{Ti}$ at an elevated temperature $\left(450^{\circ} \mathrm{C}\right)$, an ultrafine grain structure is obtained $[10,11]$. It was found that applying ECAP with a back-pressure for processing of less ductile metals is an efficient technique to improve the 
mechanical properties, instead of increasing the process temperature and die channel angle [12]. Son et al. [13] studied the effect of three types of back-pressure which is commonly used in ECAP processing of CP-Ti. Luo et al. [14] focused on structure and mechanical behavior changes of CP-Ti samples which were ECAP processed at two elevated temperatures. Zhao et al. [15] applied ECAP to Grade $1 \mathrm{Ti}$ at room temperature through eight passes, using a die with channel angle of $120^{\circ}$. They observed that the mechanical properties of the 8th pass ECAP processed sample were improved significantly and grain sizes decreased to $200 \mathrm{~nm}$ from $23 \mu \mathrm{m}$. Finally, Zhao et al. [16] could successfully perform ECAP on Grade 1 Ti through 4 passes at room temperature, but this time, by using a die with a channel angle of $90^{\circ}$. They reported that the grain size of the 4th pass ECAP processed sample decreased to $150 \mathrm{~nm}$ from $25 \mu \mathrm{m}$ and ultimate strength increased to $765 \mathrm{MPa}$ from $485 \mathrm{MPa}$. Jager et al. [3] performed four passes ECAP at room temperature on Grade $2 \mathrm{Ti}$ using a die with channel angle of $90^{\circ}$ in the presence of very high back pressure. After this procedure, they achieved a grain size of about $150 \mathrm{~nm}$. Also, they studied the microstructure and anisotropy of the mechanical properties in the ECAP processed sample. The combination of ECAP with one of the established metal forming techniques such as extrusion, rolling or forging is a common way to improve the nanostructuring of CP-Ti for medical applications [17]. Stolyarov et al. [18] reported that after cold extrusion of the 8th pass ECAP processed CP-Ti sample, the strength was increased significantly though the ductility was decreased considerably. Also, Kang et al. [19] showed that applying cold extrusion on the 5th pass ECAP processed CP-Ti sample leads to a good improvement of the strength with a large ductility loss.

In this paper, for the first time, the effects of applying isothermal warm extrusion after performing multi-pass ECAP, on the microstructure and mechanical properties of CP-Ti grade 2, 
were studied. To evaluate the effects of extrusion temperatures, the 4th pass ECAP processed sample, which had the best mechanical strengths among all of the ECAP processed samples and a good elongation to failure, was extruded at different temperatures including $300^{\circ} \mathrm{C}, 350^{\circ} \mathrm{C}$, $400^{\circ} \mathrm{C}, 450^{\circ} \mathrm{C}$ and $500^{\circ} \mathrm{C}$.

\section{Experimental procedure}

Grade 2 Ti rods were prepared with a diameter of $10 \mathrm{~mm}$ and a length of $70 \mathrm{~mm}$ as starting samples. The schematic and die parameters of ECAP and extrusion processes are demonstrated in Fig. 1. These parameters are as following: the ECAP die channel angle, $\phi=90^{\circ}$, the angle of the curvature, $\Psi=0^{\circ}$, the extrusion die half angle, $\alpha=45^{\circ}, D=10 \mathrm{~mm}$ and $d=5 \mathrm{~mm}$. The accumulated strain of this combined method is estimated from the following relationship (where $N$ is the number of ECAP passes and the other parameters are the same as mentioned in Fig. 1) [20, 21]:

$\bar{\varepsilon}=\frac{N}{\sqrt{3}}\left[2 \cot \left(\frac{\phi}{2}+\frac{\Psi}{2}\right)+\Psi \operatorname{cosec}\left(\frac{\phi}{2}+\frac{\Psi}{2}\right)\right]+4 \ln \left(\frac{\mathrm{D}}{\mathrm{d}}\right)$

The ECAP process was conducted through 1,2, 4 and 6 passes at a ram speed of $10 \mathrm{~mm} / \mathrm{min}$ at the temperature of $400^{\circ} \mathrm{C}$. In this study, among all different ECAP routes [22], $\mathrm{B}_{\mathrm{C}}$ is selected for performing ECAP. In route $\mathrm{BC}$, the sample is rotated by $90^{\circ}$ in the same direction between each pass of ECAP. It was found that route $\mathrm{BC}$ is an optimum route for reaching to a homogeneous microstructure with equiaxed grains which are separated by high-angle grain boundaries [22]. To reduce the frictional forces during the test, $\mathrm{MoS}_{2}$ paste was used on the contacting surfaces [23]. After doing each pass of ECAP, the sample was extruded to achieve a $75 \%$ area reduction at $400^{\circ} \mathrm{C}$. Since it was seen that the sample which underwent four-pass ECAP had considerably better mechanical properties than the other samples, this sample was extruded with the $75 \%$ area 
reduction at different temperatures of $300{ }^{\circ} \mathrm{C}, 350{ }^{\circ} \mathrm{C}, 400{ }^{\circ} \mathrm{C}, 450{ }^{\circ} \mathrm{C}$ and $500{ }^{\circ} \mathrm{C}$, to study the effects of extrusion temperature. After performing each pass of ECAP and warm extrusion, the tensile testing was conducted on processed samples at room temperature using an SANTAM tensile testing machine at a strain rate of $10^{-3} 1 / \mathrm{s}$. Tensile specimens were prepared, from processed samples, with the gauge length of $10 \mathrm{~mm}$ and a diameter of $3 \mathrm{~mm}$. To study the microstructures, the metallographic analysis was performed using micrographs obtained from the scanning electron microscopy (SEM), transmission electron microscopy (TEM) and SEM images obtained by crystallographic contrast using back-scattered electron. For TEM characterization, samples have been lifted using a Focused Ion Beam (FIB) in the depth direction of the sample which is referred to the axial direction of the specimen. Thin lamella TEM samples were prepared for TEM from the processed specimen using the in-situ lift-out procedure on a dual beam system (FEI Nova Nanolab 600). After the final thinning procedure, regions with a thickness less than $150 \mathrm{~nm}$ were produced for the subsequent TEM characterization. Also, a field emission gun scanning electron microscope (JEOL 7100F FEGSEM) equipped with an EBSD camera (EDAX TSL) was used for EBSD data collection under operating conditions of $20 \mathrm{kV}$ and $\sim 26$ A. The EBSD analysis was performed to yield IPFs and CIs for the samples. The Confidence Index graph revealed significant "low confidence" area. This is believed to be due to contamination of the samples introduced during the preparation stage, particularly the later polishing stages with colloidal silica. Since the EBSD graphs were inconclusive, the approach was changed to pursue TEM imaging to provide more information of the microstructure. To observe the fracture morphology of the fractured tensile samples, a field emission scanning electron microscope (FESEM model Hitachi S4160) at a voltage of $20 \mathrm{kV}$ was used. Also, microhardness measurements were recorded using a microhardness testing machine equipped 
with a Vickers indenter under a $200 \mathrm{~g}$ load and a $10 \mathrm{sec}$ load time. For each test point, three measurements were taken and averaged to find the microhardness at that point.
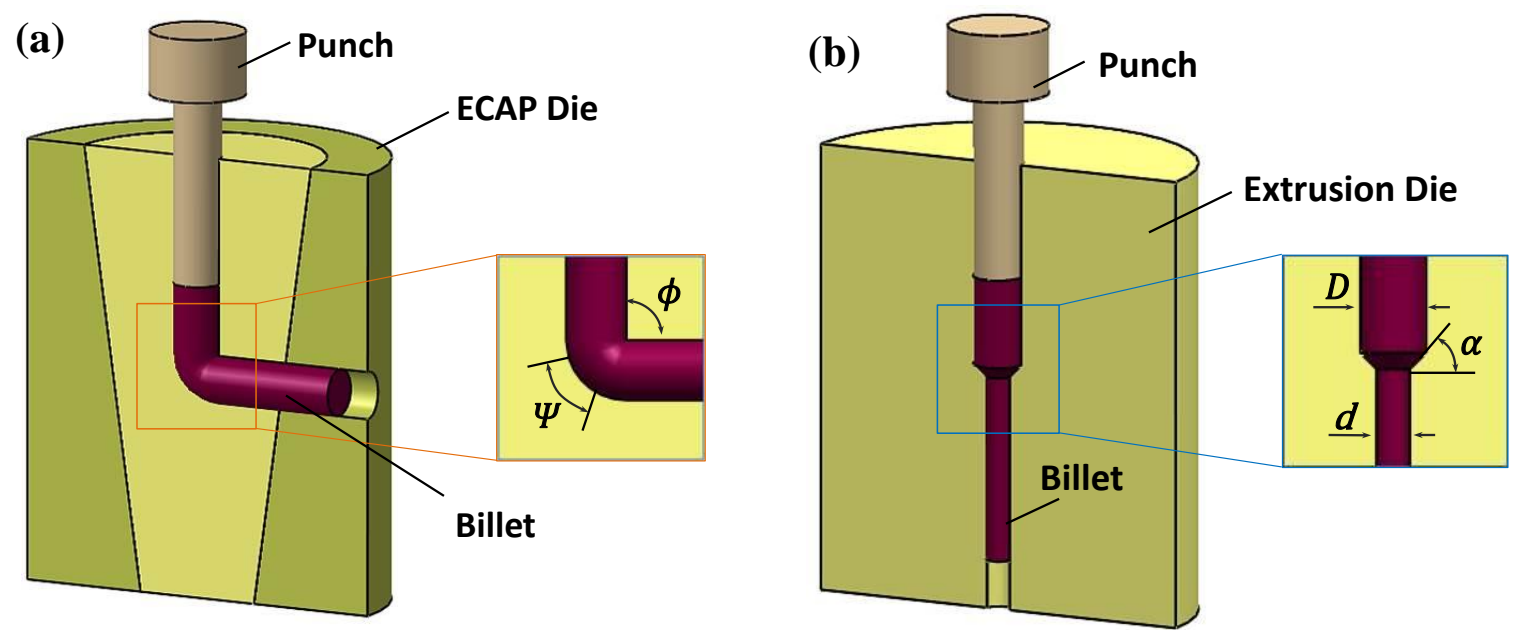

Fig. 1. Schematic of a) ECAP and b) Extrusion processes.

\section{Results and discussion}

The pictures of unprocessed, ECAP processed and extruded samples are illustrated in Fig.

2. It is seen that the extruded sample is relatively long, which is a suitable starting point to produce CP-Ti dental implants.
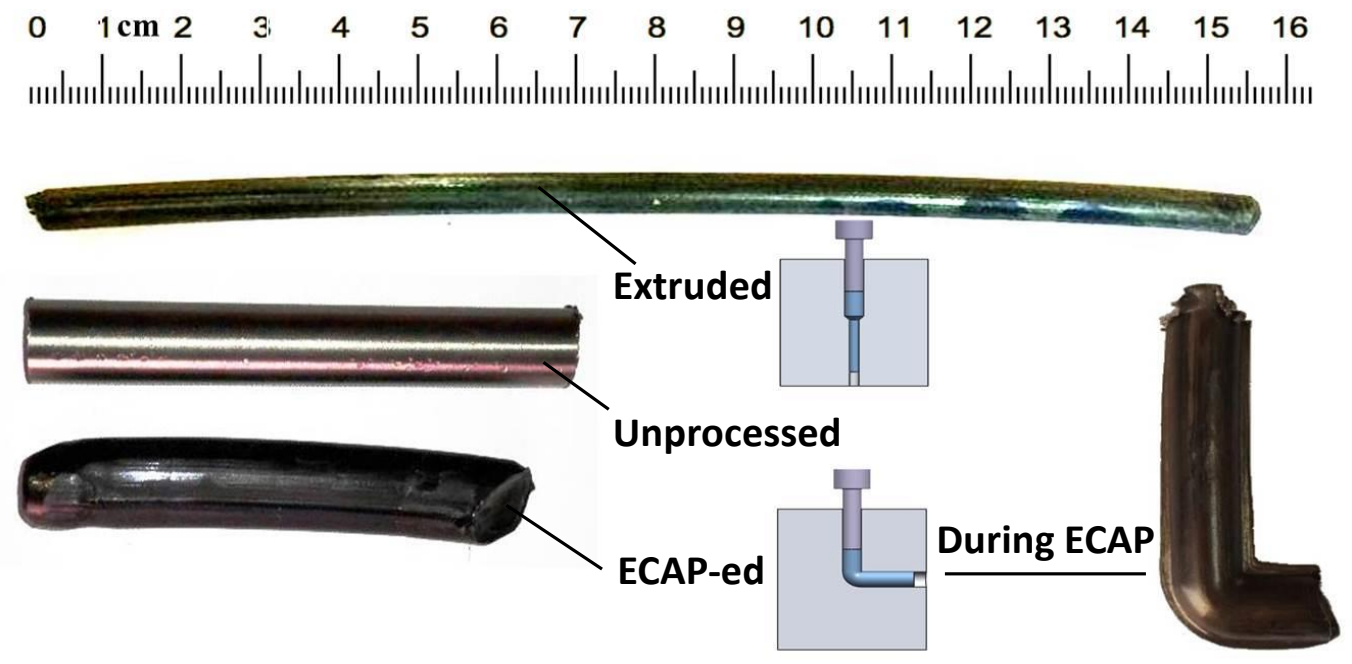

Fig. 2. Picture of unprocessed, ECAP processed and extruded samples. 


\subsection{Microstructural evolutions}

Fig. 3 shows that the average grain size of the as-received sample is $\sim 19 \mu \mathrm{m}$ and that the grains are almost equiaxed. As seen in Fig. 4(a), after applying four-pass ECAP, the average grain size in the thickness-section decreases to $\sim 177 \mathrm{~nm}$. For this sample, the distribution of grain sizes (as shown in Fig. 4(a) is wide, from less than $80 \mathrm{~nm}$ to over $280 \mathrm{~nm}$. Also, a large fraction of highangle grain boundaries is observed in Fig. 4(a). A mixed microstructure of low-angle and highangle grain boundaries is usually seen in other research, such as [24, 31, 32]. Also, studies show that with an increase in the number of ECAP passes, the fraction of high angle grain boundaries increases $[17,33,34]$. This leads to simultaneously increasing the ductility and strength of the material and also leads to improving the homogeneity of the microstructure [17]. Fig. 4(b) shows that the average grain size of the sample processed by four-pass ECAP followed by extrusion at $300^{\circ} \mathrm{C}$ is $\sim 123 \mathrm{~nm}$. Additionally, Fig. 4(b) illustrates nearly equiaxed grains with a large fraction of high-angle grain boundaries.

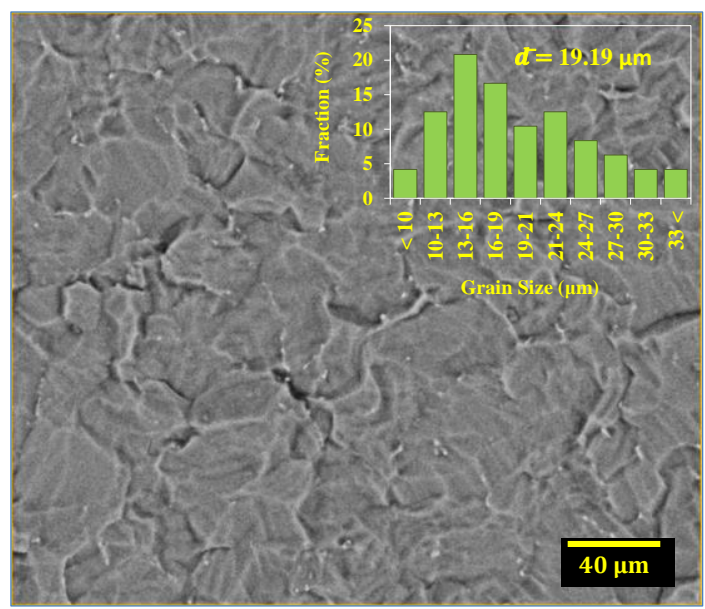

Fig. 3. SEM micrograph and grain size distributions of an as-received CP-Ti billet. 

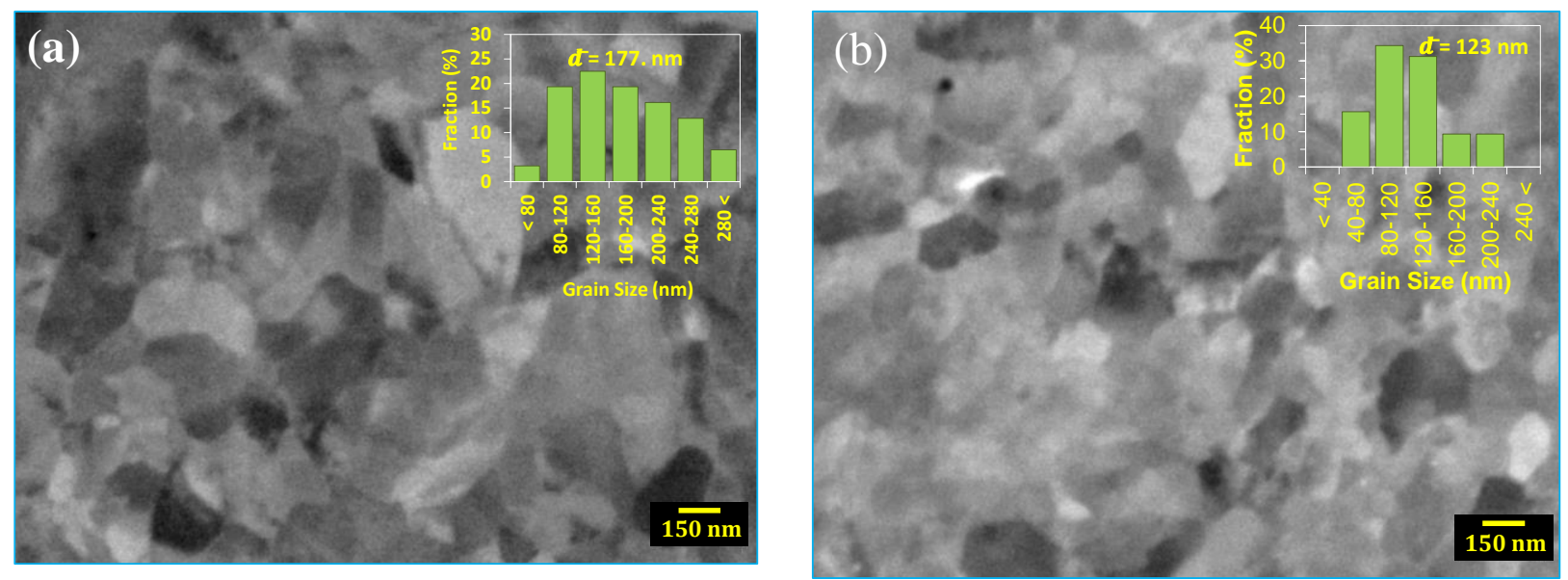

Fig. 4. SEM images obtained by crystallographic contrast using backscattered electron and grain size distributions from thickness-section of (a) a CP-Ti billet after performing four-pass ECAP and (b) a CP-Ti billet processed by four-pass ECAP followed by warm extrusion at $300^{\circ} \mathrm{C}$.

Fig. 5 demonstrates the TEM micrograph taken from the longitudinal section of the four-pass ECAP processed sample. Three types of regions can be observed in Fig. 5. (a) Regions which have almost no dislocations, labeled A, (b) Regions containing dislocation tangles and subboundaries, marked as B, and (c) Regions containing a high density of dislocations which are distributed indiscriminately, labeled C. As shown in Fig. 5, two regions of high dislocation density and elongated parallel bands are predominantly observed. As shown in Fig. 5, the grains are somewhat elongated in the longitudinal direction. After applying the first pass of ECAP, pure shear deformation occurs in the $\mathrm{CP}-\mathrm{Ti}$ sample and grains are elongated in the longitudinal direction. With an increase in the number of ECAP passes, the width of the shear bands decreases [34]. It was found that after the first pass of ECAP, twinning activity is evident. Nonetheless, after the subsequent passes of ECAP, the significance of twinning decreases [35]. Shin et al. [36] found that, in the subsequent passes of ECAP, the mechanism of deformation was altered to dislocation slip on a specific system, dependent on the type of ECAP route. Suwas et 
al. [35] saw that, up to the $3 \mathrm{rd}$ pass of ECAP on $\mathrm{CP}-\mathrm{Ti}$ at $\sim 400^{\circ} \mathrm{C}$, the material underwent restoration. This was chiefly through the mechanisms of recovery and partial recrystallization. Also, other studies indicate that almost no significant recrystallization occurs at the temperature of $450^{\circ} \mathrm{C}[17]$.
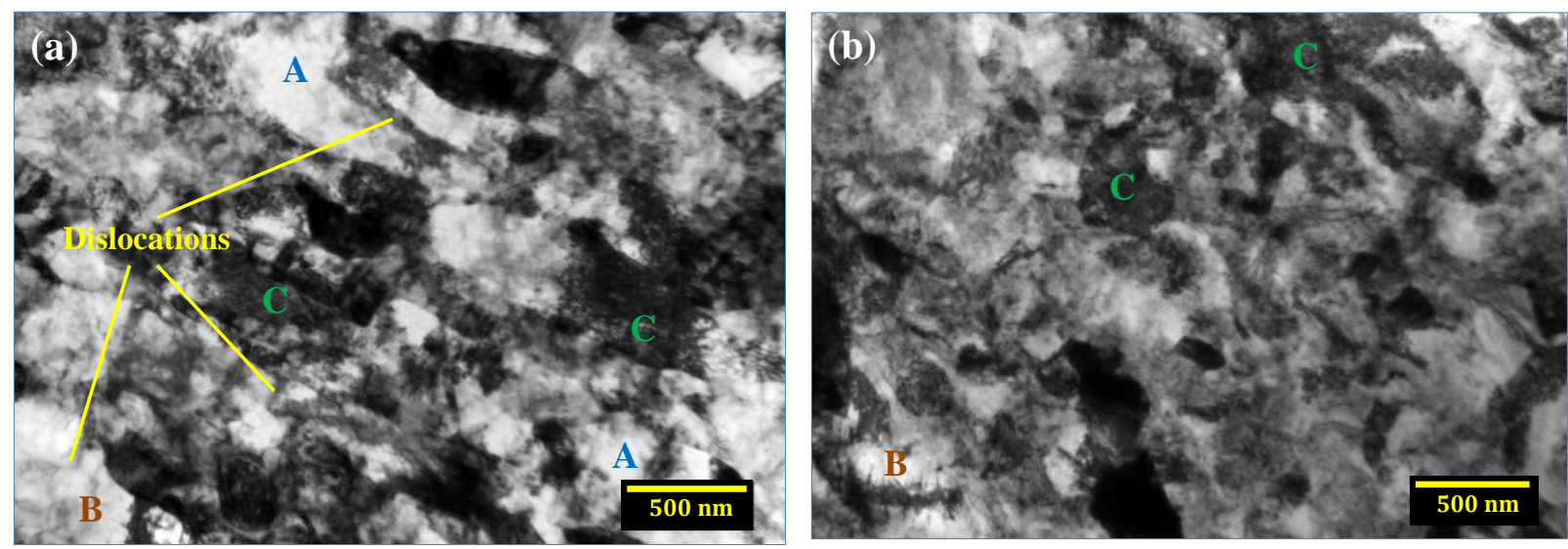

Fig. 5. TEM micrographs of (a) a longitudinal cross section and (b) a transverse cross section of the sample processed by four-pass ECAP.

\subsection{Mechanical properties}

Vickers microhardness (HV) of the as-received and ECAP processed samples are demonstrated in Fig. 6. It is seen that with the first pass of ECAP, the hardness value increases abruptly from $81.85 \mathrm{HV}$ to $184.2 \mathrm{HV}$. This increase in the hardness value after the first pass of ECAP can be due to the occurrence of dislocation hardening [29]. Also, the observed hardening after performing the first pass of ECAP can be caused by the increase in the dislocation density, the appearance of twinning, and strain hardening [30]. In the subsequent passes, hardness values increase gradually and finally reach a saturation limit. This is observed in the 4th, and 6th pass ECAP processed samples which are nearly the same. As shown in Fig. 6, the maximum value of hardness is $209.9 \mathrm{HV}$, belonging to the four-pass ECAP processed sample. Also Fig. 6 shows the obtained hardness values from the samples processed by ECAP, for a given number of passes, 
followed by warm extrusion at $400^{\circ} \mathrm{C}$. It is observed that the hardness of the as-received sample increases to $172 \mathrm{HV}$ from $81.85 \mathrm{HV}$ after extrusion. As illustrated in Fig. 6, the maximum value of hardness is $216.65 \mathrm{HV}$ belongs to the sample processed by four-pass ECAP followed by warm extrusion. Also, it is seen that both samples processed by four-pass and six-pass ECAP followed by warm extrusion have almost the same value of hardness.

The hardness values of the samples processed by four-pass ECAP followed by warm extrusion at temperatures of $300^{\circ} \mathrm{C}, 350^{\circ} \mathrm{C}, 400^{\circ} \mathrm{C}, 450^{\circ} \mathrm{C}$ and $500^{\circ} \mathrm{C}$ are shown in Fig. 6 , too. It is observed that by increasing the temperature of extrusion, the hardness value decreases. The maximum and minimum value of hardness is $231 \mathrm{HV}$ (recorded for extruded sample at $300^{\circ} \mathrm{C}$ ) and $201 \mathrm{HV}$ (recorded for extruded sample at $500^{\circ} \mathrm{C}$ ).

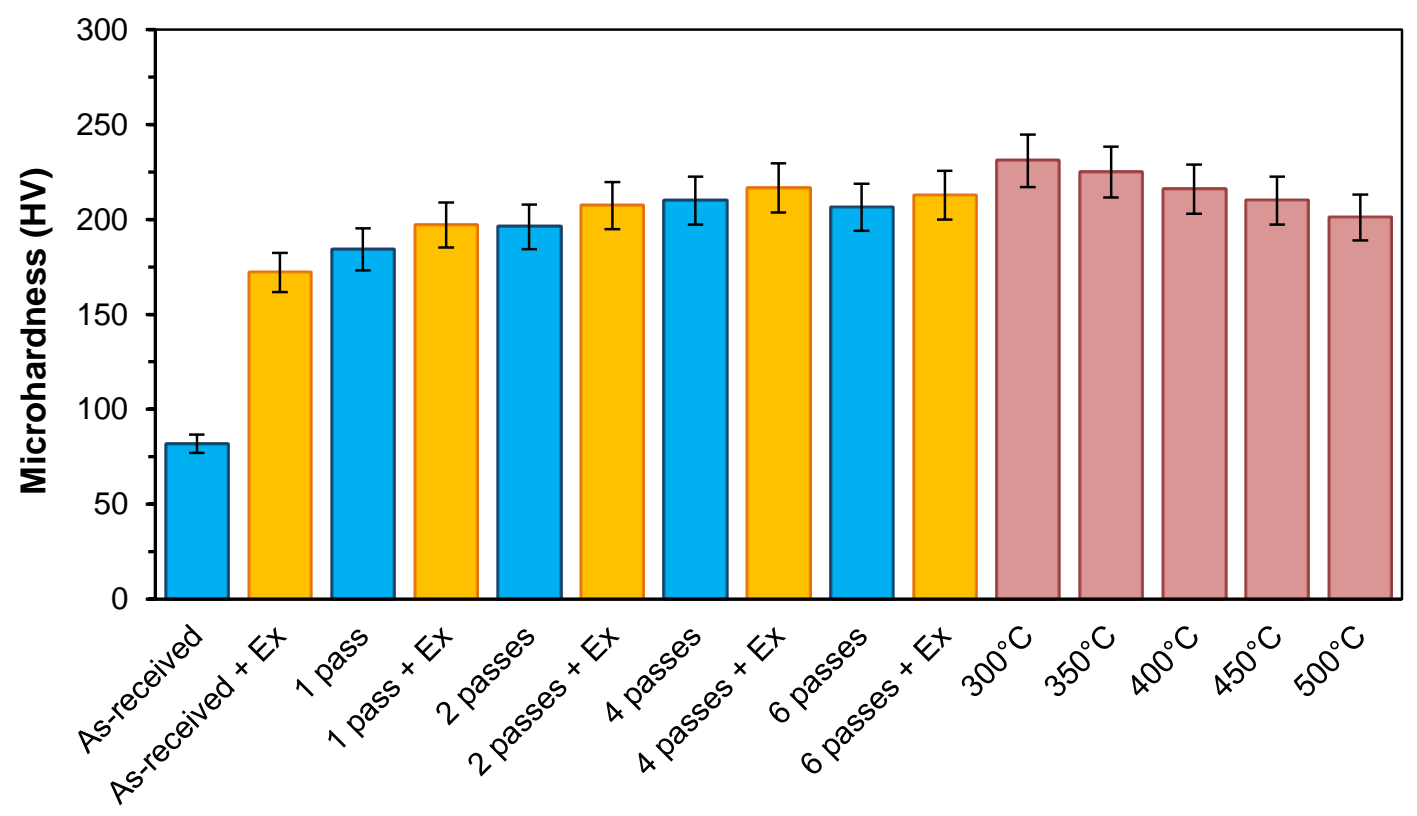

Fig. 6. Vickers microhardness results of the as-received and ECAP processed with 1, 2, 4 and 6 passes, the samples processed by ECAP followed by warm extrusion at $400^{\circ} \mathrm{C}$ and the samples processed by four-pass ECAP followed by warm extrusion at different temperatures. 
The effect of the number of ECAP passes on the engineering stress-strain curve of Grade $2 \mathrm{Ti}$ is illustrated in Fig. 7(a). The summary of the obtained tensile test results from Fig. 7(a) is demonstrated in Fig. 8(a). As seen in Fig. 8(a), after performing up to 4 passes of ECAP, the yield strength, and ultimate tensile strength increase. The maximum value of strength is obtained from the 4th pass ECAP processed sample, which has a yield strength and ultimate tensile strength of $711 \mathrm{MPa}$ and $941 \mathrm{MPa}$, respectively. The values of the same properties of the asreceived sample are $341 \mathrm{MPa}$ and $505 \mathrm{MPa}$. Also, it is seen that by increasing number of ECAP passes up to 2, the value of elongation to failure decreases (from $24 \%$ to $10.4 \%$ ) due to the formation of a UFG microstructure with very high dislocation density [24]. Fig. 7(a) shows that the values of elongation to failure of the 4th and 6th pass ECAP processed samples are greater than that of 1st and 2nd pass ECAP processed samples. This may be due to the enhancement of the fraction of high angle grain boundaries and also the improved homogeneity of the microstructure with increasing the number of passes [17, 24]. As is seen in Fig. 7(a), between 4 to 6 passes of ECAP leads to the mechanical properties of the samples tending to be saturated so that the stress-strain curves of 4 and 6 passes are relatively similar. Such saturation in grain sizes and mechanical properties was observed in other studies [24, 25]. Grain coarsening was also seen in previous studies after eight passes of ECAP [14]. Fig. 7(a) demonstrates that the value of yield strength and ultimate tensile strength of the six-pass processed sample are somewhat lower than those of four-pass. The reason for this could be the manifestation of grains growth phenomena or changes in the mechanism of plastic deformation, affected by grains size and the high process temperature of $400{ }^{\circ} \mathrm{C}$.

To evaluate the effects of applying extrusion after performing ECAP through 1,2, 4 and 6 passes, warm extrusion was conducted with a $75 \%$ area reduction at $400^{\circ} \mathrm{C}$. Fig. 7 (b) shows the 
engineering stress-strain curves for the samples processed by multi pass ECAP followed by extrusion. As shown in Fig. 7(b), after extrusion, the mechanical strength enhances but elongation to failure decreases due to the enhancement of dislocation density and presence of elongated grains along the extrusion direction. The combined technique (ECAP + extrusion) leads to an increase in the strength by the two strengthening mechanisms of grain refinement and accumulation of dislocations $[18,26]$. It is observed in Fig. 7(b) that after extruding the 4th and 6th pass ECAP processed samples, mechanical properties nearly reach to a saturation limit. Also, Fig. 7(b) shows that the sample processed by four-pass ECAP followed by extrusion has the maximum value of strengths among all samples. The yield strength and ultimate tensile strengths are $711 \mathrm{MPa}$ and $941 \mathrm{MPa}$, respectively. It is also seen that, after extrusion, the enhancement of mechanical strengths of the 4th and 6th pass ECAP processed samples are less than those of the other samples because these samples have the smallest grains sizes of all. Therefore, after extrusion, their grains size and mechanical properties reach to a saturation limit earlier than other specimens. Since it was seen that the four-pass ECAP processed sample has the maximum value of strength and also a good elongation, this sample is selected for studying the effects of warm extrusion temperature. Fig. 7(c) represents engineering stress-strain curves of the four-pass ECAP processed sample extruded at different temperatures. The summary of mechanical tensile tests results are illustrated in Fig. 8(c). It is seen that by increasing the extrusion temperature, the values of mechanical strength decrease but the elongation to failure increases due to the occurrence of grains growth phenomena and increasing the rate of recovery that leads to decreasing the dislocation density and dynamic recrystallization. The maximum mechanical strength is recorded for the sample processed by four-pass ECAP followed by warm extrusion at 
$300^{\circ} \mathrm{C}$. The yield strength and ultimate tensile strength of this sample is $787 \mathrm{MPa}$ and $1027 \mathrm{MPa}$, respectively. This sample showed elongation to failure of $8.2 \%$.

Inspections show that the mechanical properties of some samples are comparable with those of Ti-6Al-4V which is commonly used in conventional implants [27] but has alloying elements that are toxic to human health. The results of this comparison are mentioned in Table 1. It is seen that the ultimate tensile strength of the sample processed by four-pass ECAP followed by extrusion at $300^{\circ} \mathrm{C}$ is higher than that of Ti-6Al-4V. Nonetheless, its elongation to failure is slightly $(1.8 \%)$ lower than that of Ti-6Al-4V. Also, it is seen that both have nearly the same yield strength. The mechanical properties of some samples, which have a good strength and elongation to failure, are compared with the results of previous similar studies in Table 1. It is evident that improvement of yield strength and ultimate tensile strength for the samples processed four-pass ECAP followed by extrusion at $300^{\circ} \mathrm{C}, 350^{\circ} \mathrm{C}$, and $400^{\circ} \mathrm{C}$ are higher than those in [19]. Nonetheless, their strengths are lower than the strengths of sample processed in [18]. This may be due to cold extrusion that has a high hydrostatic pressure magnitude [7]. Additionally, grain growth or recrystallization phenomena that are seen at high temperatures do not occur at cold state [28]. With regards to Table 1, it is found that by applying warm extrusion, the amount of reduction of the elongation to failure in comparison with as-received condition is lower than that observed in cold extrusion state; According to table 1, this amount for Ref. [19] and Ref. [18] are about $24.8 \%$ and $19 \%$, respectively while in the present study, this amount of the sample processed by four-pass ECAP followed by extrusion at $300^{\circ} \mathrm{C}$ is $15.8 \%$. For the other samples of the present study, the amount of reduction of the elongation to failure in comparison with as-received is lower than $15.8 \%$. Also, it is observed in table 1 that the value of elongation to failure of the processed sample of Ref. [19] is higher than that of the most samples of the present study. This 
must be due to the higher initial grain size $(41.6 \mu \mathrm{m})$ of the samples of Ref. [19], and also must be due to the lower reduction rate of extrusion (25.5\%) and consequently lower applied strain in Ref. [19]. The other advantage of warm extrusion over cold extrusion is the lower required extrusion pressure.

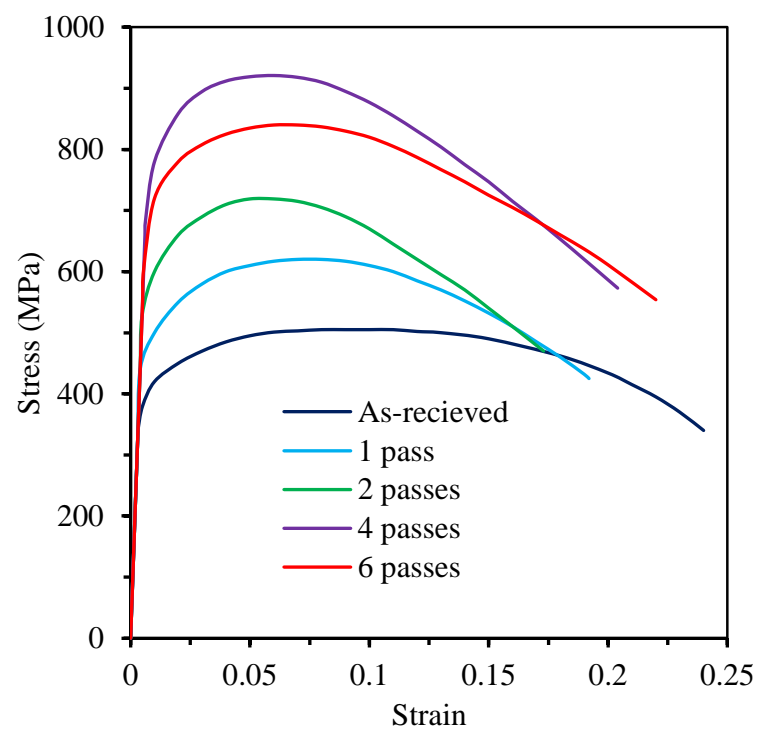

(a)

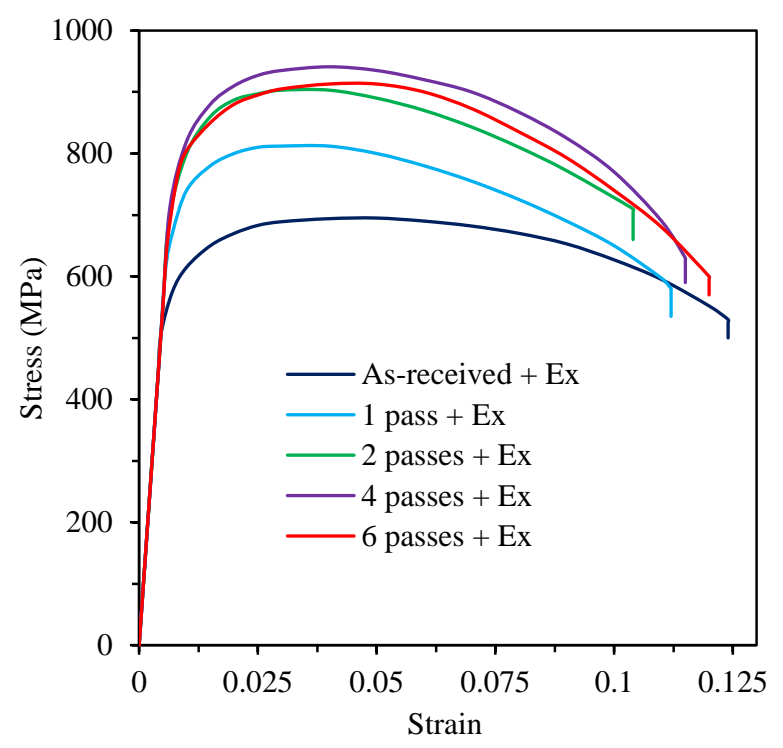

(b)

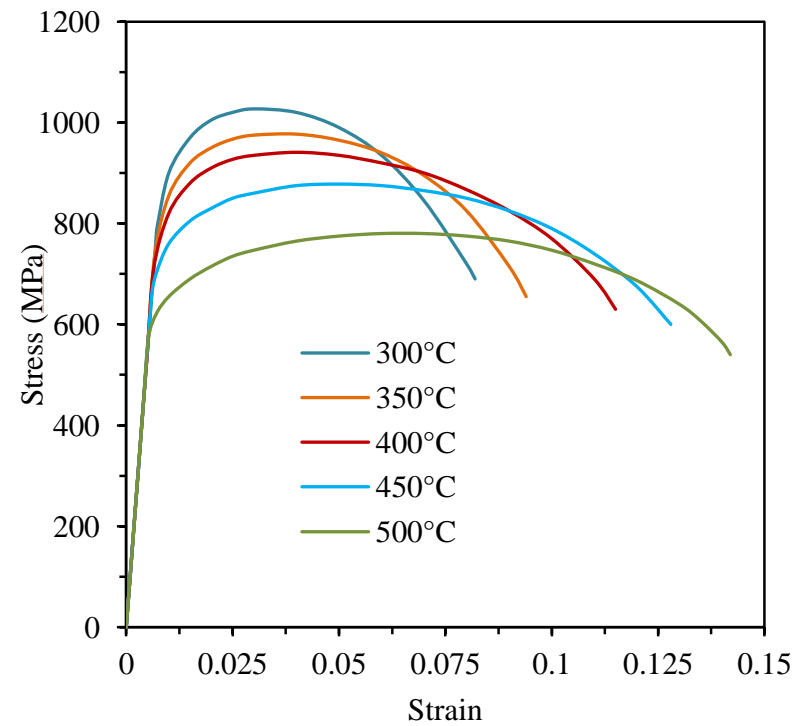

(c)

Fig. 7. Engineering stress-strain curves of (a) the as-received and ECAP processed samples with 1, 2, 4 and 6 passes, (b) the samples processed by ECAP followed by extrusion and (c) the samples processed by four-pass ECAP followed by extrusion at different temperatures. 


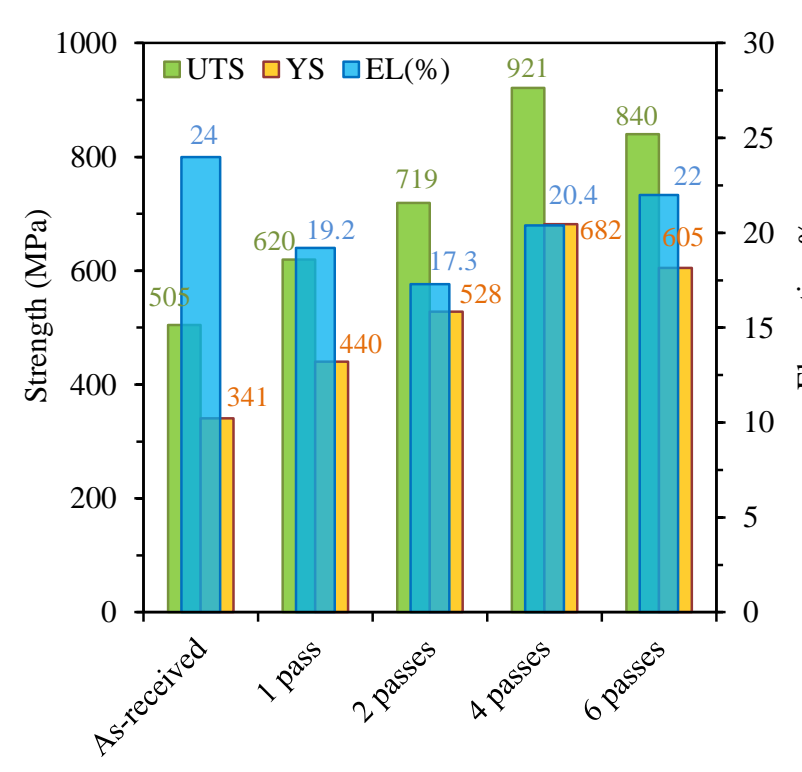

(a)

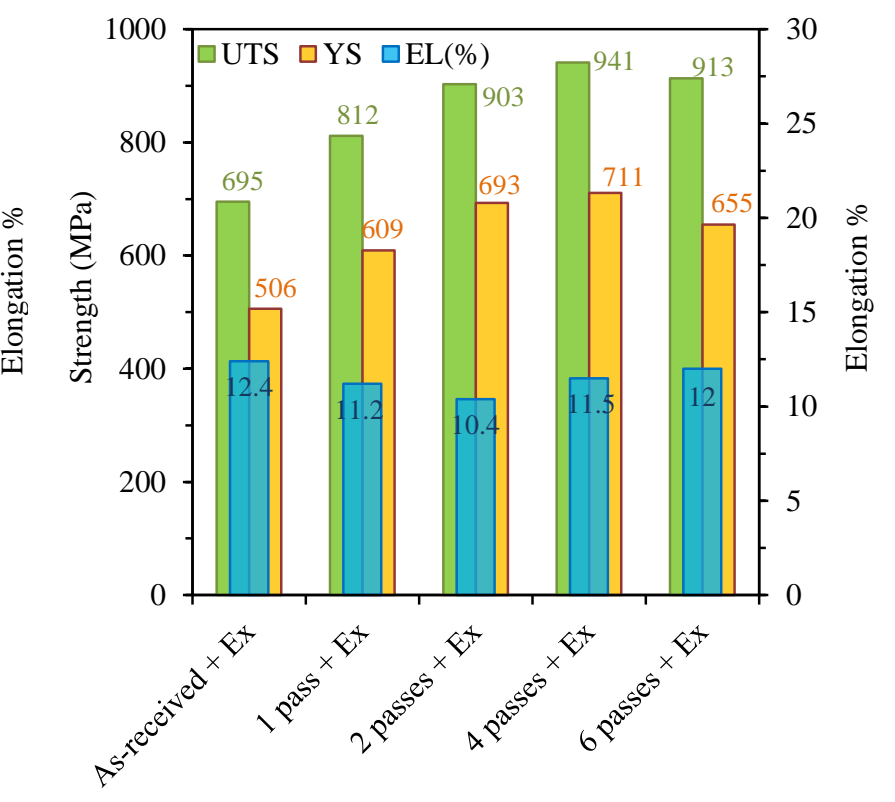

(b)

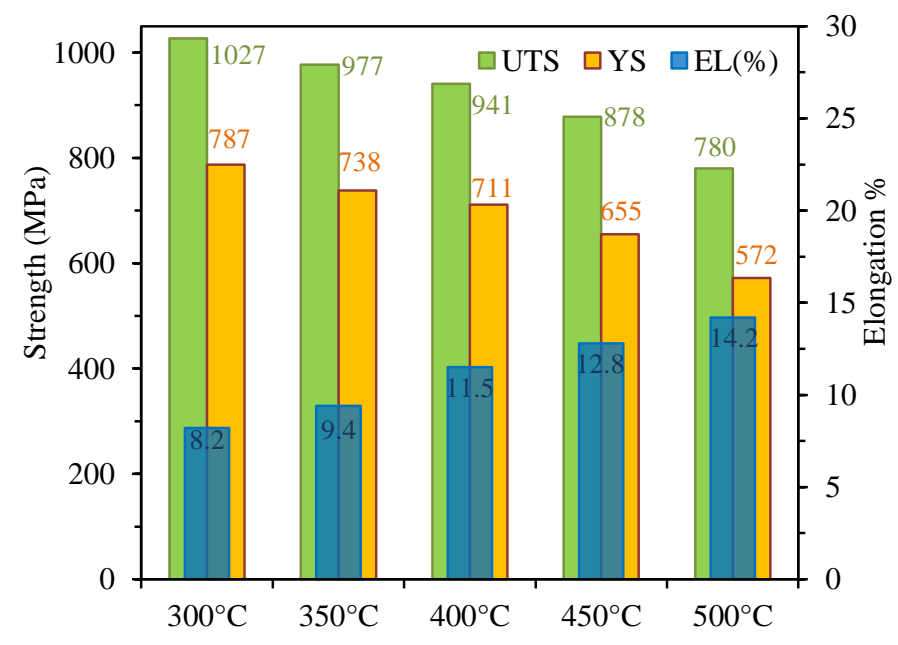

(c)

Fig. 8. The summary of obtained tensile properties including UTS, YS, and elongation from (a) Fig. 7(a), (b) Fig. 7(b), and (c) Fig 7(c).

Table 1. Comparison of obtained results from this study with those of previous studies and with properties of Ti-6Al-4V. 


\begin{tabular}{|c|c|c|c|c|c|c|}
\hline sample & $\begin{array}{c}\text { Grain } \\
\text { size } \\
(\mu \mathrm{m})\end{array}$ & $\begin{array}{l}\text { Yield } \\
\text { strength } \\
\text { (MPa) }\end{array}$ & $\begin{array}{c}\text { Ultimate } \\
\text { strength } \\
\text { (MPa) }\end{array}$ & $\begin{array}{l}\text { Elongation } \\
(\%)\end{array}$ & $\begin{array}{l}\text { Uniform } \\
\text { Elongation } \\
(\%)\end{array}$ & References \\
\hline As-received & 41.6 & 202.6 & 292.5 & 44.5 & $\sim 26-31$ & [19] \\
\hline $\begin{array}{c}\text { 5th pass ECAP }+ \\
\text { Cold extrusion }(25.5 \%)\end{array}$ & - & 708.4 & 791.9 & 19.7 & $\sim 6.5$ & [19] \\
\hline As-received & 10 & 380 & 460 & 27 & - & [18] \\
\hline $\begin{array}{c}\text { 8th pass ECAP + } \\
\text { Cold extrusion }(75 \%)\end{array}$ & - & 970 & 1050 & 8 & - & [18] \\
\hline As-received & 19.19 & 341 & 505 & 24 & 11.1 & Current study \\
\hline 4th pass ECAP + extrusion at $300^{\circ} \mathrm{C}$ & 0.123 & 787 & 1027 & 8.2 & 3.2 & Current study \\
\hline 4th pass ECAP + extrusion at $350^{\circ} \mathrm{C}$ & - & 738 & 977 & 9.4 & 3.8 & Current study \\
\hline 4th pass ECAP + extrusion at $400^{\circ} \mathrm{C}$ & - & 711 & 941 & 11.5 & 4.1 & Current study \\
\hline 4th pass ECAP + extrusion at $450^{\circ} \mathrm{C}$ & - & 655 & 878 & 12.8 & 5.2 & Current study \\
\hline 4th pass ECAP + extrusion at $500^{\circ} \mathrm{C}$ & - & 572 & 780 & 14.2 & 6.1 & Current study \\
\hline As-received + extrusion & - & 506 & 695 & 12.4 & 5.3 & Current study \\
\hline 1st pass ECAP + extrusion & - & 609 & 812 & 11.2 & 3.2 & Current study \\
\hline 2nd pass ECAP + extrusion & - & 693 & 903 & 10.4 & 2.9 & Current study \\
\hline 4th pass ECAP + extrusion & - & 711 & 941 & 11.5 & 4.1 & Current study \\
\hline 6th pass ECAP + extrusion & - & 655 & 913 & 12 & 4.9 & Current study \\
\hline 1st pass ECAP & - & 440 & 620 & 19.2 & 6.9 & Current study \\
\hline 2nd pass ECAP & - & 528 & 719 & 17.3 & 5.3 & Current study \\
\hline 4th pass ECAP & 0.178 & 682 & 921 & 20.4 & 6 & Current study \\
\hline 6th pass ECAP & - & 605 & 840 & 22 & 6.4 & Current study \\
\hline Ti-6Al-4V & - & 795 & 860 & 10 & - & {$[27]$} \\
\hline
\end{tabular}

\subsection{Fractography}

Fig. 9 shows the SEM micrographs taken from the fractured surface of the tensile test samples, which were prepared from the as-received, two-pass ECAP processed, four-pass ECAP processed and six-pass ECAP processed samples. As shown in Fig. 9(a), the fracture surface of the as-received sample contains larger dimples than the ECAP processed samples. Fig. 9(d) 
illustrates that the six-pass ECAP processed sample has a homogeneous fracture surface, which contains smaller dimples than those of other ECAP processed samples. Also, it is observed in Fig. 9(d) that the depth of dimples of the six-pass ECAP processed sample is less than those of the as-received sample. From Fig. $9(\mathrm{a}-\mathrm{d})$ it is seen that, by increasing in the number of ECAP passes, the size and depth of the dimples become less, and a more uniform fracture surface is observed. On Fig. 9(a-d), a nearly ductile fracture mechanism is seen in these four samples because of nucleation of micro voids and their subsequent growth and coalescence with each other. Fig. 9(e) shows that the sample processed by four-pass ECAP followed by warm extrusion at $300^{\circ} \mathrm{C}$, has smaller, shallower dimples and a more homogeneous fracture surface than other samples.
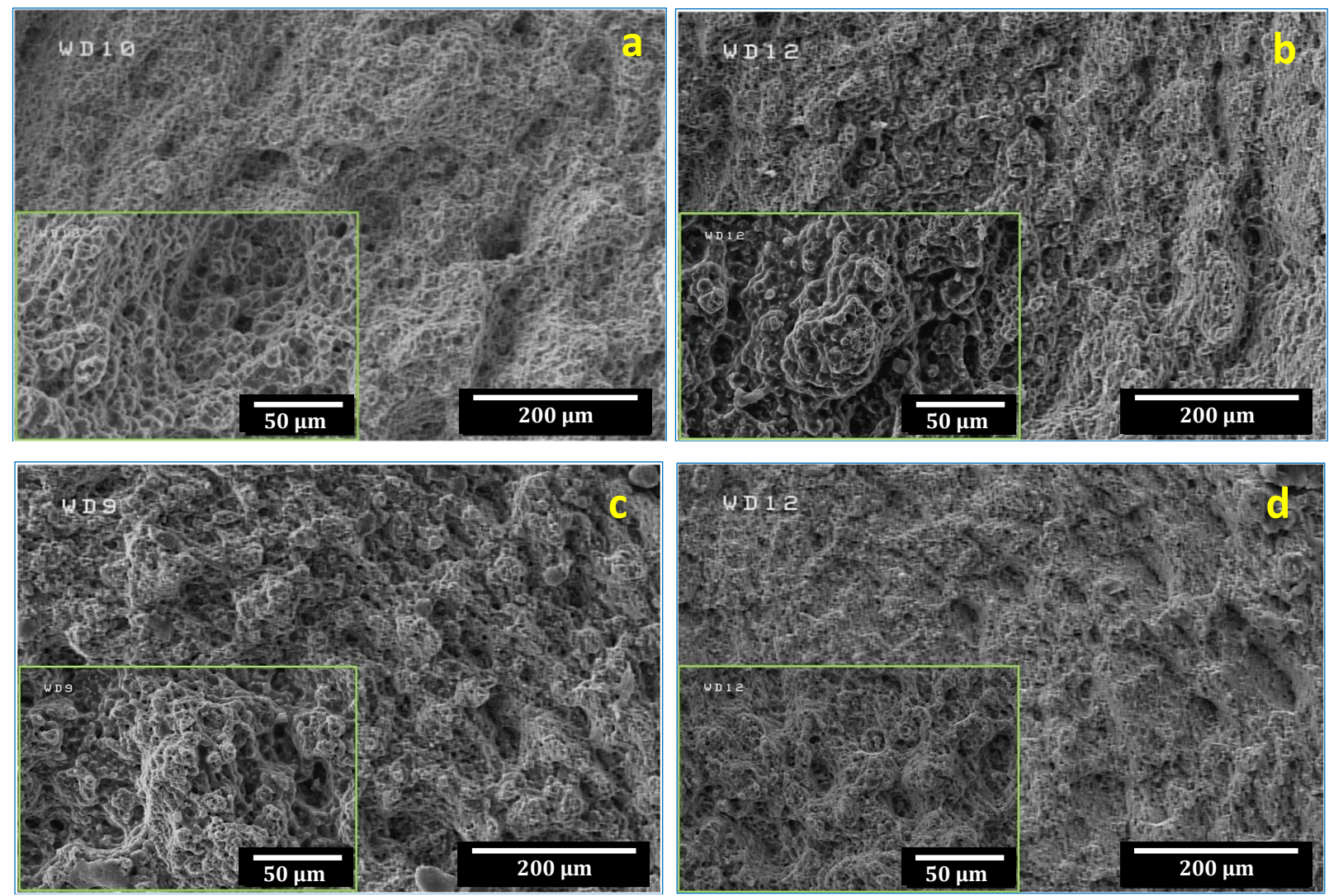


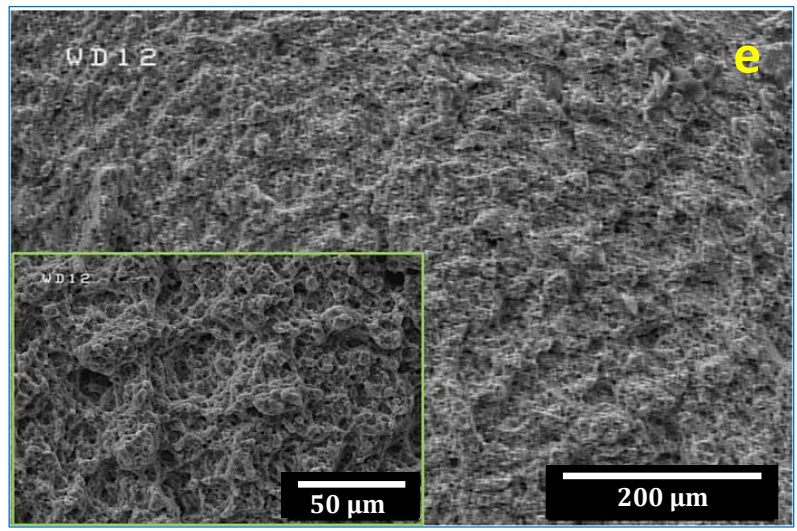

Fig. 9. SEM micrographs taken from the fractured surface of the tensile test samples prepared from the (a) as-received, (b) two-pass ECAP processed, (c) four-pass ECAP processed, (d) sixpass ECAP processed and (e) four-pass ECAP processed and subsequently extruded at $300^{\circ} \mathrm{C}$ specimens.

\section{Conclusion}

In this research, Grade $2 \mathrm{Ti}$ was processed by ECAP followed by warm extrusion. The effects of changing the number of passes of ECAP at various temperatures of warm extrusion on the microstructural and mechanical characteristics were studied. After performing four passes of ECAP, the average grain size is refined from $\sim 19 \mu \mathrm{m}$ to $\sim 178 \mathrm{~nm}$, and also the microstructure possesses UFG and high angle grain boundaries. This grain refinement led to an improvement in the: (a) yield strength by 108\% from $341 \mathrm{MPa}$ to $711 \mathrm{MPa}$, (b) ultimate tensile strength by $86 \%$ from $505 \mathrm{MPa}$ to $941 \mathrm{MPa}$ and (c) microhardness by $~ 156 \%$ from $\sim 82 \mathrm{HV}$ to $~ 210 \mathrm{HV}$. Simultaneously, elongation to failure decreases by $\sim 15 \%$ from $\sim 24 \%$ to $20.4 \%$. Also, it is found that by increasing the number of ECAP passes, the size and depth of the dimples on the fracture surface of the tensile tested specimens decreases, and a more uniform fracture surface is 
observed. After performing warm extrusion at $300^{\circ} \mathrm{C}$ on four-pass ECAP processed CP-Ti, the average grain size is refined from $\sim 19 \mu \mathrm{m}$ (in the as-received sample) to $\sim 123 \mathrm{~nm}$. Additionally, near equiaxed grains and a homogeneous fracture surface are observed. This grain size refinement can lead to an improvement in the: (a) yield strength by 131\% from $341 \mathrm{MPa}$ to $787 \mathrm{MPa}$, (b) ultimate tensile strength by 103\% from $505 \mathrm{MPa}$ to $1027 \mathrm{MPa}$ and (c) microhardness by $\sim 182 \%$ from $\sim 82 \mathrm{HV}$ to $\sim 231 \mathrm{HV}$. Simultaneously, elongation to failure decreases by $\sim 66 \%$ from $\sim 24 \%$ to $8.2 \%$. Also, it is observed that by increasing the extrusion temperature, the values of mechanical strengths and microhardness decrease, but elongation to failure increases.

\section{Acknowledgements}

This work was financially supported by Iran National Science Foundation (INSF).

\section{Reference}

[1] A. Fattah-alhosseini, A.R. Ansari, Y. Mazaheri, M. Karimi, M. Haghshenas, Materials Science and Engineering: A, 688 (2017) 218-224.

[2] F. Reshadi, G. Faraji, M. Baniassadi, M. Tajeddini, Surface and Coatings Technology, (2017).

[3] A. Jäger, V. Gärtnerova, K. Tesař, Materials Science and Engineering: A, 644 (2015) 114-120.

[4] M. Ensafi, G. Faraji, H. Abdolvand, Materials Letters, 197 (2017) 12-16.

[5] M. Eskandarzade, A. Masoumi, G. Faraji, M. Mohammadpour, X.S. Yan, Journal of Alloys and Compounds, (2016).

[6] A. Medvedev, H. Ng, R. Lapovok, Y. Estrin, T. Lowe, V. Anumalasetty, Materials Letters, 145 (2015) 308-311.

[7] G. Raab, E. Soshnikova, R. Valiev, Materials Science and Engineering: A, 387 (2004) 674-677.

[8] V. Segal, V. Reznikov, A. Drobyshevskii, V. Kopylov, Russ. Met., (1981) 99-105.

[9] S. Semiatin, D. DeLo, V. Segal, R. Goforth, N. Frey, Metallurgical and Materials Transactions A, 30 (1999) 1425-1435.

[10] P. Luo, D. McDonald, W. Xu, S. Palanisamy, M. Dargusch, K. Xia, Scripta Materialia, 66 (2012) 785788.

[11] V.V. Stolyarov, Y.T. Zhu, I.V. Alexandrov, T.C. Lowe, R.Z. Valiev, Materials Science and Engineering: A, 343 (2003) 43-50.

[12] R.Y. Lapovok, Journal of Materials Science, 40 (2005) 341-346.

[13] I.-H. Son, J.-H. Lee, Y.-T. Im, Journal of Materials Processing Technology, 171 (2006) 480-487. 
[14] P. Luo, D. McDonald, S. Zhu, S. Palanisamy, M. Dargusch, K. Xia, Materials Science and Engineering: A, 538 (2012) 252-258.

[15] X. Zhao, X. Yang, X. Liu, X. Wang, T.G. Langdon, Materials Science and Engineering: A, 527 (2010) 6335-6339.

[16] X. Zhao, X. Yang, X. Liu, C.T. Wang, Y. Huang, T.G. Langdon, Materials Science and Engineering: A, 607 (2014) 482-489.

[17] P.S. Roodposhti, N. Farahbakhsh, A. Sarkar, K.L. Murty, Transactions of Nonferrous Metals Society of China, 25 (2015) 1353-1366.

[18] V.V. Stolyarov, Y.T. Zhu, T.C. Lowe, R.Z. Valiev, Materials Science and Engineering: A, 303 (2001) 8289.

[19] D.-H. Kang, T.-W. Kim, Materials \& Design, 31 (2010) S54-S60.

[20] Y. Iwahashi, Z. Horita, M. Nemoto, T.G. Langdon, Acta materialia, 45 (1997) 4733-4741.

[21] K. Topolski, H. Garbacz, W. Pachla, K.J. Kurzydlowski, physica status solidi (c), 7 (2010) 1391-1394.

[22] K. Nakashima, Z. Horita, M. Nemoto, T.G. Langdon, Materials Science and Engineering: A, 281 (2000) 82-87.

[23] S.S. Dheda, F.A. Mohamed, Materials Science and Engineering: A, 528 (2011) 8179-8186.

[24] D. Gunderov, A. Polyakov, I. Semenova, G. Raab, A. Churakova, E. Gimaltdinova, I. Sabirov, J. Segurado, V. Sitdikov, I. Alexandrov, Materials Science and Engineering: A, 562 (2013) 128-136.

[25] Y. Chen, Y. Li, J. Walmsley, S. Dumoulin, S. Gireesh, S. Armada, P. Skaret, H. Roven, Scripta Materialia, 64 (2011) 904-907.

[26] G. Faraji, H. Kim, Materials Science and Technology, 33 (2017) 905-923.

[27] C.N. Elias, M.A. Meyers, R.Z. Valiev, S.N. Monteiro, Journal of Materials Research and Technology, 2 (2013) 340-350.

[28] W. Pachla, M. Kulczyk, M. Sus-Ryszkowska, A. Mazur, K.J. Kurzydlowski, Journal of Materials Processing Technology, 205 (2008) 173-182.

[29] K. Hajizadeh, B. Eghbali, K. Topolski, K. Kurzydlowski, Materials Chemistry and Physics, 143 (2014) 1032-1038.

[30] Y. Zhang, R.B. Figueiredo, S.N. Alhajeri, J.T. Wang, N. Gao, T.G. Langdon, Materials Science and Engineering: A, 528 (2011) 7708-7714.

[31] M. Hoseini, M.H. Pourian, F. Bridier, H. Vali, J.A. Szpunar, P. Bocher, Materials Science and Engineering: A, 532 (2012) 58-63.

[32] M.S. Rao, U. Chakkingal, T. Raghu, Transactions of the Indian Institute of Metals, 66 (2013) 357-362.

[33] I. Semenova, A. Polyakov, G. Raab, T. Lowe, R. Valiev, Journal of Materials Science, 47 (2012) 77777781.

[34] Y. Xirong, Z. Xicheng, F. Wenjie, Rare Metal Materials and Engineering, 38 (2009) 955-957.

[35] S. Suwas, B. Beausir, L. Tóth, J.-J. Fundenberger, G. Gottstein, Acta Materialia, 59 (2011) 1121-1133.

[36] D. Shin, I. Kim, J. Kim, Y. Kim, S. Semiatin, Acta Materialia, 51 (2003) 983-996. 


\section{Figures captions}

Fig. 1. Schematic of a) ECAP and b) Extrusion processes.

Fig. 2. Picture of unprocessed, ECAP processed and extruded samples.

Fig. 3. SEM micrograph and grain size distributions of an as-received CP-Ti billet.

Fig. 4. SEM images obtained by crystallographic contrast using back-scattered electron and grain size distributions from thickness-section of (a) a CP-Ti billet after performing four-pass ECAP and (b) a CP-Ti billet processed by four-pass ECAP followed by warm extrusion at $300^{\circ} \mathrm{C}$.

Fig. 5. TEM micrographs of (a) a longitudinal section and (b) a transverse section of the sample processed by four-pass ECAP.

Fig. 6. Vickers microhardness results of the as-received and ECAP processed with 1, 2, 4 and 6 passes, the samples processed by ECAP followed by warm extrusion at $400^{\circ} \mathrm{C}$ and the samples processed by four-pass ECAP followed by warm extrusion at different temperatures.

Fig. 7. Engineering stress-strain curves of (a) the as-received and ECAP processed samples with 1, 2, 4 and 6 passes, (b) the samples processed by ECAP followed by extrusion and (c) the samples processed by four-pass ECAP followed by extrusion at different temperatures.

Fig. 8. The summary of obtained tensile properties including UTS, YS, and elongation from (a) Fig. 7(a), (b) Fig. 7(b), and (c) Fig 7(c).

Fig. 9. SEM micrographs taken from the fractured surface of the tensile test samples prepared from the (a) as-received, (b) two-pass ECAP processed, (c) four-pass ECAP processed , (d) sixpass ECAP processed and (e) four-pass ECAP processed and subsequently extruded at $300^{\circ} \mathrm{C}$ specimens. 


\section{Table captions}

Table. 1. Comparison of some obtained results from this study with those of other previous similar studies and with properties of Ti-6Al-4V. 